\title{
Conserved metallomics in two insect families evolving separately for a hundred million years
}

\author{
Polychronis Rempoulakis - Negar Afshar - Beatriz Osorio - Martha Barajas-Aceves • \\ Joanna Szular · Sohel Ahmad • Thilakasiri Dammalage • Ulysses Sto Tomas • \\ Esther Nemny-Lavy • Mor Salomon • Marc J. B. Vreysen • David Nestel • \\ Fanis Missirlis
}

Received: 11 July 2014/Accepted: 14 September 2014/Published online: 9 October 2014

(C) The Author(s) 2014. This article is published with open access at Springerlink.com

\begin{abstract}
Metal cofactors are required for enzymatic catalysis and structural stability of many proteins. Physiological metal requirements underpin the evolution of cellular and systemic regulatory mechanisms for metal uptake, storage and excretion. Considering the role of metal biology in animal evolution, this paper asks whether metal content is conserved between different fruit flies. A similar metal homeostasis was previously observed in Drosophilidae flies cultivated on the same larval medium. Each species accumulated in the order of $200 \mu \mathrm{g}$ iron and zinc and approximately ten-fold less manganese and copper per gram dry weight of the adult insect. In this paper, data on the metal content in fourteen species of Tephritidae, which are major agricultural pests worldwide, are presented.
\end{abstract}

P. Rempoulakis · S. Ahmad - T. Dammalage .

U. S. Tomas - M. J. B. Vreysen

IAEA Laboratories, Insect Pest Control Laboratory,

Joint FAO/IAEA Programme of Nuclear

Techniques in Food and Agriculture,

International Atomic Energy Agency, Seibersdorf,

Austria

P. Rempoulakis · E. Nemny-Lavy · D. Nestel

Department of Entomology, Institute of Plant Protection,

Agricultural Research Organization (ARO),

The Volcani Center, Beit Dagan, Israel

N. Afshar · J. Szular

School of Biological and Chemical Sciences, Queen Mary University of London, Mile End Road, London, UK
These fruit flies can be polyphagous (e.g., Ceratitis capitata) or strictly monophagous (e.g., Bactrocera oleae) or oligophagous (e.g., Anastrepha grandis) and were maintained in the laboratory on five distinct diets based on olive oil, carrot, wheat bran, zucchini and molasses, respectively. The data indicate that overall metal content and distribution between the Tephritidae and Drosophilidae species was similar. Reduced metal concentration was observed in B. oleae. Feeding the polyphagous $C$. capitata with the diet of $B$. oleae resulted in a significant quantitative reduction of all metals. Thus, dietary components affect metal content in some Tephritidae. Nevertheless, although the evidence suggests some fruit fly species evolved preferences in the use or storage of particular metals, no metal

\footnotetext{
B. Osorio · F. Missirlis ( $\square)$

Departamento de Fisiología, Biofísica y Neurociencias, Centro de Investigación y de Estudios Avanzados del Instituto Politécnico Nacional, Av. IPN 2508, Zacatenco, Mexico City, Mexico e-mail: fanis@fisio.cinvestav.mx

M. Barajas-Aceves

Departamento de Biotecnología y Bioingenería, Centro de Investigación y de Estudios Avanzados del Instituto Politécnico Nacional, Av. IPN 2508, Zacatenco, Mexico City, Mexico

M. Salomon

Citrus Division, The Israel Cohen Institute for Biological Control, Plants Production and Marketing Board, Beit Dagan, Israel
} 
concentration varied in order of magnitude between these two families of Diptera that evolved independently for over 100 million years.

Keywords Physiology · Evolution - Genetics · Nutrition · Fruit flies of economic importance · Agriculture $\cdot$ Mediterranean fruit fly

\section{Introduction}

An obvious consideration in the evolution of flies and all organisms is the physiologic use of metals as cofactors in proteins (Cyert and Philpott 2013; Godfrey and Glass 2011; Hansch and Mendel 2009). Metal homeostasis arises from the combination of regulating dietary absorption and organismal storage and excretion to ensure tissues and cells have sufficient metal ions available for biological use (Mandilaras et al. 2013; Southon et al. 2013; Tang and Zhou 2013). Dietary absorption, in turn, is under continuous environmental influence forming a key ecological factor defining each species' niche (Forbes et al. 2009; Lang et al. 2012; Sharon et al. 2010). The extent to which specialized diets and natural selection affect the metal homeostasis systems in different insect orders has not been investigated.

Previous research has indicated that genetic change can influence metal homeostasis in Drosophila melanogaster, a commonly used fly in basic research. Mutations in the X-chromosome of $D$. melanogaster can cause dramatic changes in total body zinc accumulation (Afshar et al. 2013) and mutations in an iron transporter (Bettedi et al. 2011), or flies heterozygous for mutations in the iron storage protein ferritin (Gutierrez et al. 2013), accumulate less iron in their bodies. Similarly, flies heterozygous for mutations in Syntaxin 5 accumulate less copper (Norgate et al. 2010). Changes in metal concentrations can also arise by RNA interference (Bahadorani et al. 2010; Soriano et al. 2013; Xiao et al. 2014). Furthermore, when nine species of Drosophilidae, chosen for their differences in ecology and behavior and because their full genomes had been available (Clark et al. 2007), were raised on the same larval medium, they showed a similar metal profile, suggesting that evolutionary mechanisms exist that shape, and conserve, metal homeostasis (Sadraie and Missirlis 2011). In this paper, we addressed the hypothesis that this relative stability of laboratory-maintained Drosophilidae metallomes is also conserved in other fruit flies.

Along with the family Drosophilidae, the family Tephritidae (true fruit flies) belongs to the insect order Diptera. The Tephritidae form a highly variable group of approximately five thousand described species belonging to five hundred genera (Aluja and Norrbom 1999; White and Elson-Harris 1994). The larvae in the majority of these species are phytophagous, feeding exclusively on plant tissues and pose a significant threat to agriculture in many regions of the world. The host range varies significantly among the different species, with some being highly polyphagous, e.g., the Mediterranean fruit fly Ceratitis capitata has 356 recorded fruit and vegetable hosts (Liquido et al. 1991; Hancock et al. 2000; De Meyer et al. 2002). Other species are strictly monophagous, e.g., the olive fruit fly Bactrocera oleae, which feeds only on the olive fruit mesocarp (Tzanakakis 2003), or oligophagous, feeding on a small range of hosts, e.g., the South American cucurbit fruit fly Anastrepha grandis. Colonies of fruit flies were maintained at the Insect Pest Control Laboratory (IPCL) of the joint Food and Agriculture Organization-International Atomic Energy Agency (FAO-IAEA) program of Nuclear Techniques in Food and Agriculture of the United Nations. Appropriate artificial larval diets provide all the necessary nutrients for the development of the flies. Rearing of the polyphagous and oligophagous flies on a common artificial medium is possible, but certain species have unique requirements and the use of natural hosts as rearing medium is still unavoidable. This is the case with species attacking Cucurbitaceae, like A. grandis (Gomes Silva and Malavasi 1993) and the African fruit fly Dacus ciliatus (Zur et al. 2009), which have both been maintained on their natural hosts (zucchinis) for a number of generations.

In this study, the metal contents in the bodies of newly emerged adults belonging to 14 different species of fruit fly, representing the major pests, were measured. With the exception of $D$. ciliatus and one population of $C$. capitata all other insects were maintained at the IPCL facilities. Whereas previous studies have compared species only within a single family representing perhaps 10-12 million years of separation, this resource was used to evaluate evolutionary mechanisms operating on insect metal homeostasis over a much longer period by comparing the 
families Drosophilidae and Tephritidae, which are estimated to have been divergent for 100 million years (Beverley and Wilson 1984; Wulbeck and Simpson 2000). In addition, a dietary variable (an olive oil supplement) was introduced experimentally to test its effect on metal accumulations and address the theory that the oil reduces tissue metal content. Only few previous studies have addressed whether olive oil might have metal chelating properties, and none of these involved tests with experimental animals (Briante et al. 2003; Paiva-Martins and Gordon 2005; Visioli and Galli 2002).

\section{Materials and methods}

Insects

In view of unfavorable climatic conditions in the area (Seibersdorf, Austria), fruit flies are not considered a quarantine pest in Austria and hence, the IPCL has a unique collection of fruit fly strains and species that allows for parallel and comparative studies of many different species. The origin and typical hosts of all strains used in this study are listed in Table 1. The number of generations the colonies were maintained at the IPCL and the history of each line are shown. Fruit flies representing four genera (Bactrocera, Anastrepha, Dacus and Ceratitis) were selected for analysis and experimentation. Bactrocera was represented with nine species, Anastrepha with three species, and Ceratitis and Dacus with one species each. The fly colonies were maintained in controlled bioclimatic rooms at a temperature of $25 \pm 2{ }^{\circ} \mathrm{C}$, humidity at $65 \pm 5 \%$, and a photoperiod of light to dark cycles of 14:10 h. Eggs were collected daily from cages containing mature reproductive adults and they were placed on a thin paper towel on top of a thick layer of larval medium in $5 \mathrm{~L}$ trays. These trays were transferred to higher humidity ( $90 \%$ ) chambers where they

Table 1 Characteristics and origin of species used in this study

\begin{tabular}{|c|c|c|c|c|}
\hline Species and level of phagy & Natural host* & Origin of strain & Population & Generation \\
\hline 1-1 Bactrocera oleae-m & Olives & Italy & Wild type & 5 \\
\hline 1-2 Bactrocera oleae & & Greece & Laboratory & $>500$ \\
\hline 1-3 Bactrocera oleae & & Israel & Lab-wild hybrid & 100 \\
\hline 2-1 Bactrocera dorsalis $-p$ & Apples, guava, banana & Thailand & Wild type & 20 \\
\hline 2-2 Bactrocera dorsalis & & China, Yunnan & Laboratory & 6 \\
\hline 2-3 Bactrocera dorsalis & & Hawai & Lab GSS strain & 65 \\
\hline 3 Bactrocera tryoni- $p$ & Apples, apricots, coffee & Australia & Laboratory & 32 \\
\hline 4 Bactrocera cucurbitae-o & Pumpkins & Mauritius & Wild type & 19 \\
\hline 5 Bactrocera carambolae $-p$ & A. carambola, Syzigium, banana & Surinam, Paramaribo & Wild type & 16 \\
\hline 6 Bactrocera papaya-p & Banana, mango, papaya & Malaysia, Serdang & Wild type & 12 \\
\hline 7 Bactrocera invadens $-p$ & Kashew nut, citrus, pine apple & Kenya & Laboratory & 37 \\
\hline 8 Bactrocera zonata-o & Peach, guava, mango & Mauritius & Laboratory & 19 \\
\hline 9 Bactrocera philippinensis-p & Breadfruit, Sizygium, mango & Philippines, Guimaras & Wild type & 17 \\
\hline 10 Anastrepha ludens $-p$ & M. indica, prunus, citrus & Mexico & Laboratory & 25 \\
\hline 11 Anastrepha fraterculus $-p$ & $P$. java, prunus, citrus & Brazil, Vacaria & Wild type & 22 \\
\hline 12 Anastrepha grandis-o & Pumpkins & Brazil** & Wild type & 3 \\
\hline 13-1 Ceratitis capitata-p & $\sim 356$ hosts & Argentina & Wild type & 70 \\
\hline 13-2 Ceratitis capitata & & Austria & Lab GSS strain & 8 \\
\hline 13-3 Ceratitis capitata & & Israel & Laboratory & $\sim 500$ \\
\hline 14 Dacus ciliatus-o & Pumpkins & South Israel & Laboratory & 50 \\
\hline 15 Drosophila melanogaster $-p$ & Yeasts & Italy, Tannes & Wild type & $>500$ \\
\hline
\end{tabular}

* Host data from (White and Elson-Harris 1994) and from the invasive species compendium cabi.org

** Collected from fruits imported from Brazil

$m$ Monophagus, $o$ oligophagus, $p$ polyphagous, GSS genetic sexing strain 
were held until their pupation in vermiculite. Pupae were sieved and transferred to a dry room. After approximately 10 days the adults emerged in large Perspex cages $(50 \times 50 \times 40 \mathrm{~cm})$, with adult diet (sugar:yeast hydrolysed 3:1) and water provided ad libitum. Two to four days following emergence, a large number of flies $(>500)$ from each species were collected in plastic vials, freeze dried using standard procedures and shipped for metal content analysis. $D$. melanogaster was used as a control.

\section{Diets}

The larval stage of the different fly species were reared in the following media.

Olive fly diet (i) (olive fly and Mediterranean fruit fly): a-cellulose $28 \%$, brewer's yeast $7.6 \%$, soya hydrolyzed $3 \%$, sugar $2 \%$, olive oil $2 \%$, Tween 80 $0.75 \%$, potassium sorbate $0.05 \%$, nipagin $0.2 \%$, $\mathrm{HCl} 0.45 \%$, Water $55 \%$.

Carrot diet (ii) (Anastrepha and Bactrocera species): carrot powder $15 \%$, brewer's yeast $7 \%$, sodium benzoate $0.24 \%$, nipagin $0.19 \%$, $\mathrm{HCl} 0.8 \%$, water $77 \%$.

Mediterranean fruit fly diet (iii) (Mediterranean fruit fly): wheat bran $24.2 \%$, brewer's yeast $8.1 \%$, sugar $16.2 \%$, sodium benzoate $0.5 \%$, citric acid $1.8 \%$, water $49.2 \%$. A variation of this diet was also used where indicated: wheat bran $26.8 \%$, brewer's yeast $8.1 \%$, sugar $12.1 \%$, nipagin $0.4 \%$, $\mathrm{HCl} 1.6 \%$, water $51 \%$.

Zucchini diet (iv) (A. grandis and D. ciliatus): fresh, organically grown zucchinis.

Drosophila diet (v) (D. melanogaster): molasses $12.5 \%$, brewer's yeast $10 \%$, agar $1.6 \%$, gelatin $0.3 \%$, propionic acid $1 \%$, water $74.6 \%$.

All ingredients were purchased from local suppliers and extra virgin olive oil was used where indicated.

\section{Atomic absorption spectrometry}

Insects were freeze dried, weighed, and $200 \mu \mathrm{g}$ were digested with nitric acid under heating conditions previously described (Sadraie and Missirlis 2011). Total $\mathrm{Cu}, \mathrm{Fe}, \mathrm{Mn}$ and $\mathrm{Zn}$ concentration in the insects were measured in the flame atomic absorption spectrometry (Avanta M System 300 GF 3000 S/N 10288). Prior to analysis the samples were filtered to remove impurities and any undigested material (BarajasAceves 2005).
Diet manipulation and fly growth and reproduction

For the experiment of the Mediterranean fruit fly reared in its own and in olive fly diet with $(2 \%)$ and without $(0 \%)$ olive oil, a laboratory colony was used as source. Eggs were collected daily ( $\sim 24 \mathrm{~h}$ old) and were transferred to the three different diets. Essential biological parameters (egg-pupa recovery, pupal weight, and adult emergence) were recorded following the (FAO/IAEA/USDA 2003). The number of eggs placed on the diet in trays was counted (500 eggs in $50 \mathrm{~g}$ of diet for each replicate, 30 replicates for each diet) and following pupation the number of successfully developed pupae was used to estimate egg-pupa recovery. Ten pupae per replicate were individually weighted after 6 days of pupation to estimate average pupal weight. The percentage of emergence per replicate was estimated from the produced pupae. Adults for metal estimations were freeze-dried, and their wet and dry weight recorded. For the determination of lipid content, 30 male and 30 female newly emerged individuals per dietary treatment were collected and stored individually at $20{ }^{\circ} \mathrm{C}$ until chemical analysis. A protocol using digestion with sulfuric acid and vanillin reagent (Warburg and Yuval 1996) was used to extract lipids from individual flies, and the standard curve was constructed using incremental concentrations of Triolein (Sigma, St. Louis, MO) as the lipid standard. The lipid determination was performed by reading the vanillin-reaction in 96-well microplates at $490 \mathrm{~nm}$ in an ELISA-reader (Nestel et al. 2004). For soluble protein quantification, a different set of individuals (10 males and 10 females) per dietary scheme were used. Flies were individually homogenized in PBS, and protein development was conducted using the Bradford reagent (Bio-Rad laboratories, Richmond, CA). Protein content per fly was determined by reading at $595 \mathrm{~nm}$, using bovine serum albumin (Sigma, St. Louis, MO) as a standard (Nestel et al. 2004).

\section{Statistical analysis}

All metal content data (species-replications) were subjected to one-way analysis of variance (ANOVA), followed by Tukey's HSD post hoc pairwise comparisons. Ordination and classification of specific metalcontents in the Tephritidae and Drosophilidae species 
was inferred using the average metal content per species in a principal component analysis. The first principal component was further employed to classify species in a dendrogram system. All statistical inferences were conducted with the software JMP ${ }^{\circledR}$ for Windows (SAS).

\section{Results}

Metal content in recently established laboratory populations and long-established laboratory cultures of the same species

For each of the species, B. oleae, B. dorsalis and $C$. capitata, a recently established colony and additional populations of a different origin but long established in the laboratory (at least 40 years for Mediterranean fruit fly and olive fly colonies and 5 years for $B$. dorsalis) were compared (Table 1). The latter were assumed to have undergone significant bottleneck selection. Accumulation of iron, zinc, copper and manganese during larval and pupal development was taken to be the content at adult emergence (Table 2). A one-way ANOVA revealed significant differences between species and populations. C. capitata showed significantly higher iron than the two Bactrocera species. Moreover, the Israeli population of $C$. capitata showed significantly higher levels of zinc and copper too, possibly related to the slightly modified diet on which they were cultivated (footnote to Table 2 and "Materials and methods" section above) or to genetic background, but otherwise little differences were observed between populations of the same species, whether colonies were recently caught or longstanding. Similar patterns and lack of differences between populations of the same species were already described for various Drosophila species and strains (Sadraie and Missirlis 2011).

Metal content in species of Tephritidae

Eleven additional species of Tephritidae and a wild type D. melanogaster as control were added to the analysis (Table 3). Fruit fly species differed significantly in their metal content $(p<0.001)$. Bactrocera oleae showed a low concentration of all four metals compared to the averages of all other species tested. In contrast, $C$. capitata metal contents were generally in the upper part of the range. The high degree of zinc accumulation in A. grandis was notable; a finding unlikely to be attributable to the zucchini diet of this oligophagous species, as D. ciliatus larvae were also cultivated on zucchini but did not accumulate zinc to a similar extent (Table 3). Bactrocera papayae was found to accumulate more manganese compared to all other species, and B. oleae was strikingly manganesepoor. In more than half of the $B$. oleae samples manganese was undetectable and not even included in the ANOVA.

Trends in metal accumulation in genera of Tephritidae

Species were pooled together by genus of Tephritidae to detect patterns of metal accumulation at this systematic level (Table 4). Four genera were compared: the Bactrocera were represented by nine species, the Anastrepha by three, whereas only one representative was available for Ceratitis and Dacus. Differences between genera in metal accumulation were significant for the four metals tested $(p<0.001$ for iron, zinc and copper, $p<0.05$ for manganese): the Bactrocera showed low concentration of copper, the Anastrepha accumulated high levels of zinc and Ceratitis accumulated high levels of iron. Although these differences were statistically significant, they still amounted to less than a two-fold variation. Only manganese content in $D$. ciliatus varied by a factor greater than two, but as manganese concentrations showed high variability (an observation also made in the Drosophilidae; Sadraie and Missirlis 2011) the probability of this finding being the effect of chance remains considerable. More representative species from the Dacus and Ceratitis genera need to be tested before our observations can be generalized.

Conserved metal accumulation in two Diptera families

A principal component analysis was carried out using the average values for each metal, including the values previously determined in nine wild-type Drosophilidae species (Sadraie and Missirlis 2011). Cluster analysis is presented in a dendrogram form (Fig. 1). The results grouping together Drosophilidae and Tephritidae species suggest that relative metal content is a poor predictor for evolutionary relatedness between fly species and families of flies (Han and Ro 2009; 
Table 2 Metal content (mg metal/g dry weight) of recently eclosed adult flies presented as averages \pm standard deviation with number of independent biological replicates indicated as $\mathrm{N}$

\begin{tabular}{lllllll}
\hline Species/Origin & Diet & $\mathrm{N}$ & $\mathrm{Fe}(\mathrm{mg} / \mathrm{g})$ & $\mathrm{Zn}(\mathrm{mg} / \mathrm{g})$ & $\mathrm{Cu}(\mathrm{mg} / \mathrm{g})$ & $\mathrm{Mn}(\mathrm{mg} / \mathrm{g})$ \\
\hline Bactrocera oleae & & & & & & \\
1-1 Italy-wild & $\mathrm{i}$ & 7 & $0.13 \pm 0.03^{\mathrm{cd}}$ & $0.13 \pm 0.02^{\mathrm{bc}}$ & $0.008 \pm 0.003^{\mathrm{b}}$ & $0.008 \pm 0.001^{\mathrm{b} *}$ \\
1-2 Greece-lab & $\mathrm{i}$ & 8 & $0.14 \pm 0.05^{\mathrm{cd}}$ & $0.12 \pm 0.03^{\mathrm{bc}}$ & $0.010 \pm 0.003^{\mathrm{b}}$ & $0.010 \pm 0.001^{\mathrm{ab} *}$ \\
1-3 Israel-lab & $\mathrm{i}$ & 7 & $0.11 \pm 0.03^{\mathrm{d}}$ & $0.11 \pm 0.02^{\mathrm{c}}$ & $0.009 \pm 0.004^{\mathrm{b}}$ & $0.006 \pm 0.000^{\mathrm{b} *}$ \\
Bactrocera dorsalis & & & & & \\
2-1 Thailand-wild & ii & 9 & $0.19 \pm 0.03^{\mathrm{cd}}$ & $0.19 \pm 0.04^{\mathrm{b}}$ & $0.008 \pm 0.002^{\mathrm{b}}$ & $0.041 \pm 0.025^{\mathrm{ab}}$ \\
2-2 China-lab & ii & 9 & $0.19 \pm 0.05^{\mathrm{cd}}$ & $0.18 \pm 0.06^{\mathrm{bc}}$ & $0.008 \pm 0.002^{\mathrm{b}}$ & $0.025 \pm 0.006^{\mathrm{ab} * *}$ \\
2-3 Hawai-lab & ii & 9 & $0.18 \pm 0.08^{\mathrm{cd}}$ & $0.18 \pm 0.04^{\mathrm{bc}}$ & $0.008 \pm 0.004^{\mathrm{b}}$ & $0.051 \pm 0.041^{\mathrm{ab}}$ \\
Ceratitis capitata & & & & & \\
13-1 Argentina-wild & iii & 9 & $0.24 \pm 0.09^{\mathrm{bc}}$ & $0.17 \pm 0.04^{\mathrm{bc}}$ & $0.006 \pm 0.002^{\mathrm{b}}$ & $0.028 \pm 0.016^{\mathrm{ab}}$ \\
13-2 Austria-lab & iii & 9 & $0.30 \pm 0.13^{\mathrm{ab}}$ & $0.18 \pm 0.05^{\mathrm{bc}}$ & $0.010 \pm 0.004^{\mathrm{b}}$ & $0.054 \pm 0.016^{\mathrm{a}}$ \\
13-3 Israel-lab & iii*** & 7 & $0.41 \pm 0.04^{\mathrm{a}}$ & $0.27 \pm 0.03^{\mathrm{a}}$ & $0.028 \pm 0.003^{\mathrm{a}}$ & $0.041 \pm 0.006^{\mathrm{ab}}$ \\
Statistics**** & & & & & \\
1-way ANOVA F ratio & $\mathrm{F}_{(8,65)}$ & & $12.8, p<0.001$ & $10.3, p<0.001$ & $35.1, p<0.001$ & $3.7, p<0.002^{* * * * *}$ \\
\hline
\end{tabular}

Different populations, wild and lab-adapted, from three representative species are shown

* Average of three determinations shown because in other samples (Mn) was below the detection limit

** Average of six determinations shown because in other samples (Mn) was below the detection limit

*** This diet contained different preservatives

$(\mathrm{HCl} 1.6 \%$ and Nipagin $0.4 \%$ instead of Sodium Benzoate $0.5 \%$ and Citric Acid $1.8 \%$ )

**** Within columns, averages followed by different letters [a, b, c, d] indicate statistically significant differences in pair-wise comparisons using the Tukey HSD test and $p<0.05$

$* * * * * \mathrm{~F}_{(8,50)}$

Stratikopoulos et al. 2009). As an example, Drosophila virilis and Drosophila erecta, previously found to accumulate iron and other metals differentially compared to the other Drosophilidae, grouped very closely with B. oleae and C. capitata, respectively. Depicting graphically the relative metal content of representative species demonstrates remarkably similar patterns between all species regardless of their statistical clustering. Drosophila yakuba and Anastrepha fraterculus and the outliers already mentioned were chosen as examples to illustrate this point (Fig. 1).

The average metal composition was calculated for all fourteen species included in this study and compared with the average metal composition of nine species of Drosophilidae (Sadraie and Missirlis 2011). Despite the differences in food composition between the species belonging to these different families, they showed similar iron, zinc or manganese concentrations and only a small difference could be detected for copper, which accumulated at a lower level in the Tephritidae (Table 4). Thus, the pattern that emerged from the comparisons between the two families of Diptera suggests that metal homeostasis is well conserved between these insect families.

Metal accumulation in $C$. capitata cultivated on different diets

The possible effect of olive oil on metal accumulation was tested in a preliminary experiment by cultivating D. melanogaster in its normal diet supplemented with $2 \%$ olive oil. It was found that the addition of olive oil to the diet of this species resulted in significant lethality with fewer than $10 \%$ of larvae initiating metamorphosis to become fully developed pupae. The few adults able to emerge from this treatment were also short-lived. As a result, a single sample was obtained for our metal determination assay. In contrast to $D$. melanogaster, the polyphagous $C$. capitata thrived on the B. oleae diet, with $48 \%$ of the embryos reaching the pupal stage on the $C$. capitata normal diet and $30 \%$ when cultivated on the B. oleae diet. Well 
Table 3 Metal content (mg metal/g dry weight) of Tephritidae species

\begin{tabular}{llrllll}
\hline Species & Diet & $\mathrm{N}$ & $\mathrm{Fe}(\mathrm{mg} / \mathrm{g})$ & $\mathrm{Zn}(\mathrm{mg} / \mathrm{g})$ & $\mathrm{Cu}(\mathrm{mg} / \mathrm{g})$ & $\mathrm{Mn}(\mathrm{mg} / \mathrm{g})$ \\
\hline 1. Bactrocera oleae & i & 22 & $0.13 \pm 0.04^{\mathrm{c}}$ & $0.12 \pm 0.03^{\mathrm{c}}$ & $0.009 \pm 0.003^{\mathrm{bc}}$ & $0.008 \pm 0.002^{\mathrm{d}}$ \\
2. Bactrocera dorsalis & ii & 27 & $0.18 \pm 0.04^{\mathrm{bc}}$ & $0.18 \pm 0.05^{\mathrm{b}}$ & $0.008 \pm 0.003^{\mathrm{c}}$ & $0.040 \pm 0.021^{\mathrm{c}}$ \\
3. Bactrocera tryoni & ii & 9 & $0.18 \pm 0.04^{\mathrm{bc}}$ & $0.22 \pm 0.03^{\mathrm{b}}$ & $0.010 \pm 0.002^{\mathrm{abc}}$ & $0.038 \pm 0.013^{\mathrm{cd}}$ \\
4. Bactrocera cucurbitae & ii & 9 & $0.15 \pm 0.05^{\mathrm{bc}}$ & $0.21 \pm 0.05^{\mathrm{b}}$ & $0.010 \pm 0.002^{\mathrm{abc}}$ & $0.037 \pm 0.017^{\mathrm{cd}}$ \\
5. Bactrocera carambolae & ii & 9 & $0.23 \pm 0.05^{\mathrm{ab}}$ & $0.21 \pm 0.05^{\mathrm{b}}$ & $0.009 \pm 0.002^{\mathrm{abc}}$ & $0.044 \pm 0.016^{\mathrm{bcd}}$ \\
6. Bactrocera papayae & ii & 9 & $0.24 \pm 0.05^{\mathrm{ab}}$ & $0.23 \pm 0.05^{\mathrm{b}}$ & $0.010 \pm 0.005^{\mathrm{abc}}$ & $0.100 \pm 0.048^{\mathrm{a}}$ \\
7. Bactrocera invadens & ii & 9 & $0.19 \pm 0.03^{\mathrm{bc}}$ & $0.18 \pm 0.02^{\mathrm{bc}}$ & $0.006 \pm 0.003^{\mathrm{c}}$ & $0.078 \pm 0.043^{\mathrm{ab}}$ \\
8. Bactrocera zonata & ii & 9 & $0.20 \pm 0.07^{\mathrm{bc}}$ & $0.22 \pm 0.08^{\mathrm{b}}$ & $0.006 \pm 0.003^{\mathrm{c}}$ & $0.049 \pm 0.028^{\mathrm{bc}}$ \\
9. Bactrocera philippinensis & ii & 9 & $0.23 \pm 0.06^{\mathrm{ab}}$ & $0.20 \pm 0.05^{\mathrm{b}}$ & $0.011 \pm 0.004^{\mathrm{abc}}$ & $0.024 \pm 0.006^{\mathrm{cd}}$ \\
10. Anastrepha ludens & ii & 9 & $0.21 \pm 0.05^{\mathrm{bc}}$ & $0.24 \pm 0.04^{\mathrm{b}}$ & $0.017 \pm 0.004^{\mathrm{a}}$ & $0.048 \pm 0.015^{\mathrm{bc}}$ \\
11. Anastrepha fraterculus & ii & 9 & $0.19 \pm 0.04^{\mathrm{bc}}$ & $0.22 \pm 0.06^{\mathrm{b}}$ & $0.010 \pm 0.002^{\mathrm{abc}}$ & $0.039 \pm 0.026^{\mathrm{cd}}$ \\
12. Anastrepha grandis & iv & 8 & $0.17 \pm 0.05^{\mathrm{bc}}$ & $0.34 \pm 0.09^{\mathrm{a}}$ & $0.012 \pm 0.004^{\mathrm{abc}}$ & $0.028 \pm 0.011^{\mathrm{cd}}$ \\
13. Ceratitis capitata & iii & 25 & $0.31 \pm 0.12^{\mathrm{a}}$ & $0.20 \pm 0.06^{\mathrm{b}}$ & $0.014 \pm 0.010^{\mathrm{a}}$ & $0.041 \pm 0.018^{\mathrm{c}}$ \\
14. Dacus ciliatus & iv & 7 & $0.17 \pm 0.03^{\mathrm{bc}}$ & $0.23 \pm 0.04^{\mathrm{b}}$ & $0.016 \pm 0.005^{\mathrm{a}}$ & $0.011 \pm 0.002^{\mathrm{cd}}$ \\
15. Drosophila melanogaster & v & 9 & $0.19 \pm 0.03^{\mathrm{bc}}$ & $0.23 \pm 0.07^{\mathrm{b}}$ & $0.015 \pm 0.003^{\mathrm{abc}}$ & $0.017 \pm 0.008^{\mathrm{cd}}$ \\
Statistics* & & & & & &
\end{tabular}

* Within columns, averages followed by different letters [a, b, c, d] indicate statistically significant differences in pair-wise comparisons using the Tukey HSD test and $p<0.05$

$* * \mathrm{~F}_{(8,149)}$

Table 4 Metal content (mg metal/g dry weight) per genus of Tephritidae and comparison with the Drosophilidae family

\begin{tabular}{llllll}
\hline Species/Genus/Family & $\mathrm{N}$ & $\mathrm{Fe}(\mathrm{mg} / \mathrm{g})$ & $\mathrm{Zn}(\mathrm{mg} / \mathrm{g})$ & $\mathrm{Cu}(\mathrm{mg} / \mathrm{g})$ & $\mathrm{Mn}(\mathrm{mg} / \mathrm{g})$ \\
\hline Bactrocera sp. & 112 & $0.18 \pm 0.06^{\mathrm{b}}$ & $0.18 \pm 0.05^{\mathrm{b}}$ & $0.009 \pm 0.003^{\mathrm{b}}$ & $0.045 \pm 0.035^{\mathrm{a}}$ \\
Anastrepha sp. & 26 & $0.19 \pm 0.05^{\mathrm{b}}$ & $0.26 \pm 0.09^{\mathrm{a}}$ & $0.013 \pm 0.004^{\mathrm{a}}$ & $0.039 \pm 0.020^{\mathrm{ab}}$ \\
Ceratitis capitata & 25 & $0.31 \pm 0.12^{\mathrm{a}}$ & $0.20 \pm 0.06^{\mathrm{b}}$ & $0.014 \pm 0.010^{\mathrm{a}}$ & $0.041 \pm 0.018^{\mathrm{ab}}$ \\
Dacus ciliatus & 7 & $0.17 \pm 0.03^{\mathrm{b}}$ & $0.23 \pm 0.04^{\mathrm{ab}}$ & $0.016 \pm 0.005^{\mathrm{a}}$ & $0.011 \pm 0.002^{\mathrm{b}}$ \\
Statistics & & & & $14.6, p<0.001$ & $3.3, p<0.05^{* *}$ \\
$\quad$ 1-way ANOVA F ratio & $\mathrm{F}_{(3,166)}$ & $22.7, p<0.001$ & $12.4, p<0.001$ & $0.011 \pm 0.003$ & $0.042 \pm 0.024$ \\
Average Tephritidae & 14 & $0.20 \pm 0.04$ & $0.21 \pm 0.05$ & $0.018 \pm 0.006$ & $0.028 \pm 0.013$ \\
Average Drosophilidae*** & 9 & $0.22 \pm 0.07$ & $0.18 \pm 0.07$ & & \\
\hline
\end{tabular}

* Within columns, averages followed by different letters [a, b, c, d] indicate statistically significant differences in pair-wise comparisons using the Tukey HSD test and $p<0.05$

*** $\mathrm{F}_{(3,151)}$

**** Data from nine Drosophila species taken from (Sadraie and Missirlis 2011)

over $90 \%$ of these pupae successfully emerged in both conditions and gave rise to adults of similar body weight. Total protein and lipid contents were also determined per individual, controlling for gender (Fig. 2). Only minor differences in protein and lipid content were contrasted by a dramatic decrease for zinc, copper and manganese (Table 5). The zinc and manganese concentration were well below the Tephritidae average. Iron was also reduced, though only mildly, remaining at a relatively high value. Finally, C. capitata was compared with or without olive oil. The addition of olive oil further diminished zinc and copper accumulation and also caused a detectable reduction in iron accumulation. Therefore, it appears 


\section{Drosophilidae}

\section{D. virilis}

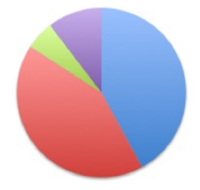

\section{D. yakuba}

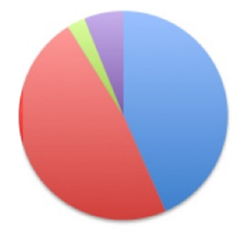

D. erecta

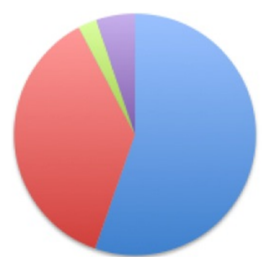

Tephritidae

B. oleae

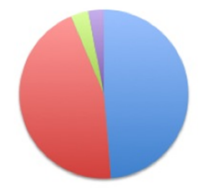

A. fraterculus

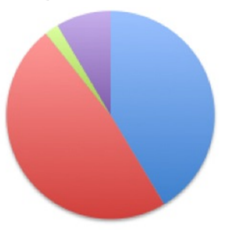

C. capitata

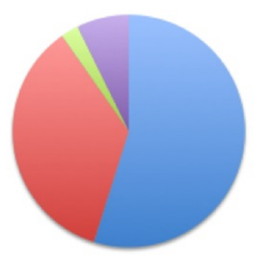

Fig. 1 Cluster analysis based on the average values of metal composition of 23 Dipteran species belonging to Tephritidae and Drosophilidae families. Clustering by 1st principal component. The relative distributions of iron (blue), zinc (red), manganese (purple) and copper (green) of three representative species that cluster together are depicted on the left, with circle area scaled to total metal content (per g dry weight). For

that olive oil has metal chelating activity, at least as indirectly judged by its effect on metal accumulation when fed to insects (Fig. 2 and Table 5).

\section{Discussion}

Metal homeostasis in Drosophilidae and Tephritidae

In nine species of Drosophilidae iron and zinc concentrations were about $200 \mu \mathrm{g} / \mathrm{g}$ of the adult dry weight, and manganese and copper to about one tenth of this level (Sadraie and Missirlis 2011). A similar result holds in the present study for 14 species of Tephritidae, suggesting a conservative selection mechanism has been in place in natural populations over a period of approximately 100 million years (Beverley and Wilson 1984; Wulbeck and Simpson 2000). An alternative

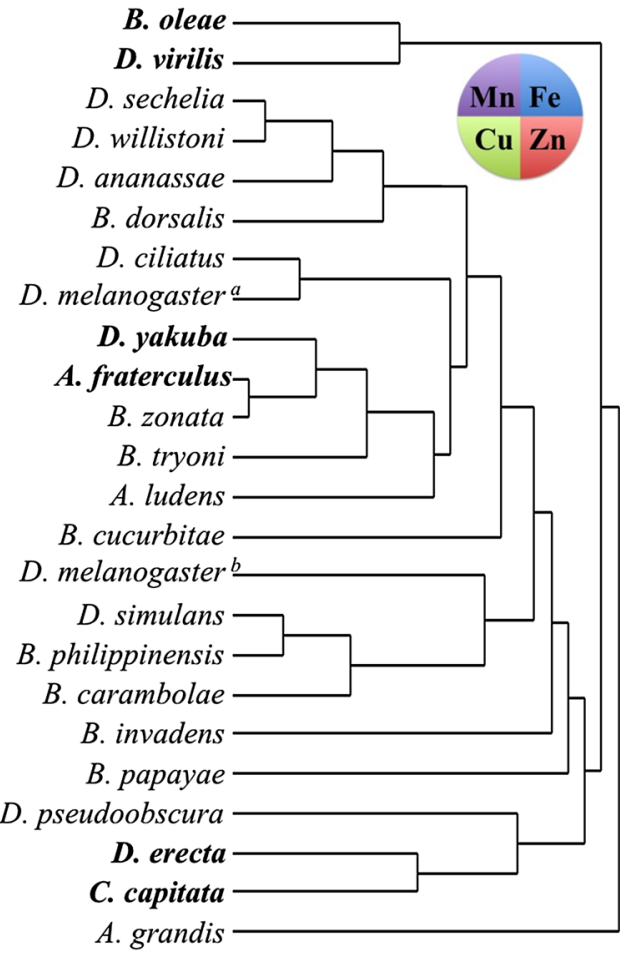

numerical values see Table 3 for the Tephritidae and (Sadraie and Missirlis 2011) for the Drosophilidae. Drosophila melanogaster appears in both references and was raised in different diets between the two studies. It is notable that Tephritidae outliers $B$. oleae and $A$. grandis have a very narrow host range and were raised on different diets

explanation is that the fruit fly genomic mutations do not normally affect the metallome, however mutations affecting metal accumulation are known in laboratory strains of D. melanogaster (for example reducing iron, Bettedi et al. 2011; reducing copper, Hua et al. 2011; reducing zinc, Afshar et al. 2013; reducing manganese, Freeman et al. 2013), which in general are non-lethal and show little effect on fitness.

\section{Effect of diet on metal accumulation}

An established way to alter metal content of a given stain of D. melanogaster is to feed the larvae a diet enriched with a metal salt (Bettedi et al. 2011; BonillaRamirez et al. 2011; Georgieva et al. 1999; Mora et al. 2014) or a metal chelator (Gutierrez et al. 2010; Sanokawa-Akakura et al. 2010; Singh et al. 2013; Soriano et al. 2013; Yang et al. 2005). This manipulation readily alters the levels of metal accumulated 


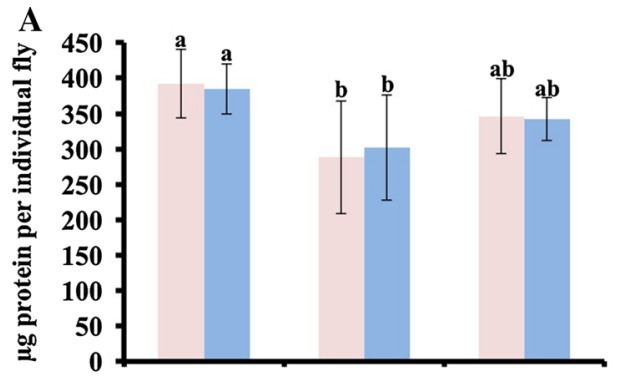

B
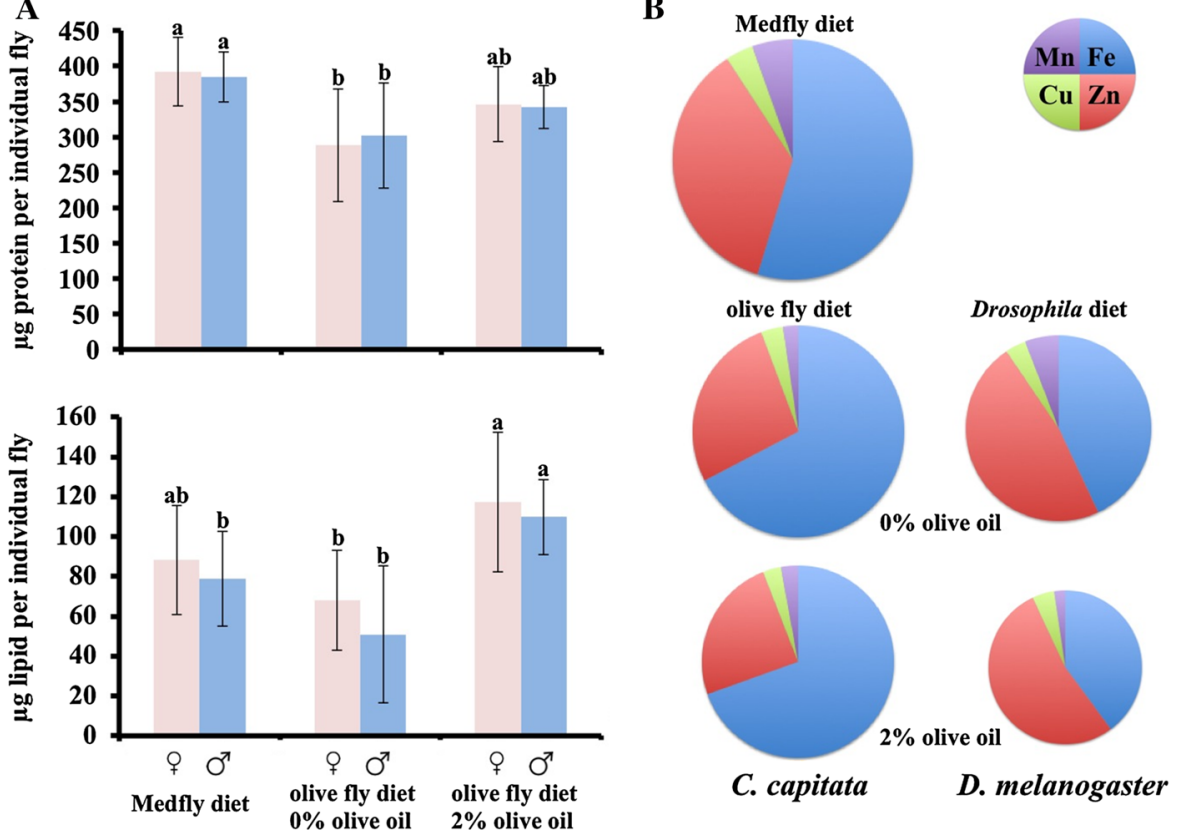

Fig. 2 Effect of three different dietary schemes on C. capitata protein, lipid and metal content. a A population of $C$. capitata cultivated in Israel (13-3) was raised on the diet of B. oleae (i$2 \%$ olive oil) and also on a similar diet but omitting the olive oil (i-0 \%). Soluble protein and lipid content (higher and lower graphs, respectively) was determined for thirty individual male flies and thirty females per dietary treatment. Mediterranean fruit fly protein content was significantly lower when the flies were raised on $0 \%$ olive oil $\left(\mathrm{F}_{2,27}\right.$ ratio $=6.62 ; p=0.004$ for males, $\mathrm{F}_{2,27}$ ratio $=7.02 ; p=0.003$ for females), and lipid

content was significantly higher when they were raised on olive fly diet containing $2 \%$ olive oil $\left(\mathrm{F}_{2,26}\right.$ ratio $=10.95$; $p=0.0004$ for males, $\mathrm{F}_{2,30}$ ratio $=8.08 ; p=0.001$ for females). b The relative distribution of iron (blue), zinc (red), manganese (purple) and copper (green) of the C. capitata on the three different diets is depicted on the left, with circle area scaled to total metal content (for values see Table 5). A single experiment with $D$. melanogaster is also shown for comparison. Olive oil leads to a reduction of metal content per mg dry weight in both species tested

Table 5 Effect of switching Ceratitis capitata on the diet of Bactrocera oleae on metal content

\begin{tabular}{lllllll}
\hline Species & Diet* $^{*}$ & $\mathrm{~N}$ & $\mathrm{Fe}(\mathrm{mg} / \mathrm{g})$ & $\mathrm{Zn}(\mathrm{mg} / \mathrm{g})$ & $\mathrm{Cu}(\mathrm{mg} / \mathrm{g})$ & $\mathrm{Mn}(\mathrm{mg} / \mathrm{g})$ \\
\hline 3-3 Ceratitis capitata & $\mathrm{iii}-0 \%$ & 7 & $0.41 \pm 0.04^{\mathrm{a}}$ & $0.27 \pm 0.03^{\mathrm{a}}$ & $0.028 \pm 0.003^{\mathrm{a}}$ & $0.041 \pm 0.006^{\mathrm{a}}$ \\
3-3 Ceratitis capitata & $\mathrm{i}-2 \%$ & 7 & $0.34 \pm 0.03^{\mathrm{b}}$ & $0.12 \pm 0.02^{\mathrm{c}}$ & $0.015 \pm 0.002^{\mathrm{c}}$ & $0.014 \pm 0.003^{\mathrm{b}}$ \\
3-3 Ceratitis capitata & $\mathrm{i}-0 \%$ & 6 & $0.40 \pm 0.04^{\mathrm{a}}$ & $0.16 \pm 0.03^{\mathrm{b}}$ & $0.020 \pm 0.003^{\mathrm{b}}$ & $0.014 \pm 0.003^{\mathrm{b}}$ \\
Statistics** & & & & & & \\
1-way ANOVA F ratio & $\mathrm{F}(2,17)$ & & $7.7, p<0.005$ & $54.5, p<0.001$ & $42.4, p<0.001$ & $101.6, p<0.001$ \\
Drosophila melanogaster & $\mathrm{v}-2 \%$ & 1 & 0.12 & 0.16 & 0.014 & 0.007 \\
Drosophila melanogaster & $\mathrm{v}-0 \%$ & 1 & 0.19 & 0.21 & 0.016 & 0.026 \\
\hline
\end{tabular}

* Olive oil inclusion as indicated

** Within columns, averages followed by different letters [a, b, c, d] indicate statistically significant differences in pair-wise comparisons using the Tukey HSD test and $p<0.05$

in the adult flies. Therefore, it was expected that flies raised on different diets might as a consequence show changes in their metal homeostasis unrelated to their different genetic background. The two species with the most striking differences in this study were B. oleae, which had low levels of metals tested and $C$. capitata, which had high levels. These two species are also opposites with respect to their range of natural hosts. B. oleae is strictly monophagous feeding only on the olive fruit mesocarp (Tzanakakis 2003), whereas $C$. 
capitata feeds on hundreds of fruits or vegetables worldwide (Liquido et al. 1991; Hancock et al. 2000; De Meyer et al. 2002). This allowed testing the effect of cultivating $C$. capitata on a specialized B. oleae diet, but not vice versa. The result of this experiment showed that the diet is a parameter that cannot be ignored in metal homeostasis studies as $C$. capitata showed a two-fold reduction in zinc and copper and a three-fold reduction in manganese when cultivated on a B. oleae diet (Table 5). The effect on iron accumulation was minimal, giving rise to two further considerations. On the one hand, it may be important to test the sustainability of $C$. capitata on this diet for a few generations before reassessing its impact on iron homeostasis. A strong maternal contribution of ferritin iron has been reported in D. melanogaster (GonzálesMorales et al. 2014), which raises the question on the conservation of a similar mechanism in C. capitata resulting in a delay of any dietary effects on metal chelation. On the other hand, when grouping the insects according to their natural range of hosts and looking for any correlating change in any of the four metals, a clear series for iron content (as $\mu \mathrm{g} / \mathrm{g}$ dry weight) could be detected, with monophagus $B$. oleae $(0.13)<$ oligophagus (see Table 1) flies $(0.17)<$ polyphagus flies $(0.21)<C$. capitata $(0.31)$. At present, we do not know if there is any causal reason for this correlation or whether it has ecological relevance.

\section{Metal chelating properties of olive oil}

Olive oil constitutes a central ingredient of the human diet in the Mediterranean countries and a large number of studies have been carried out on its nutritional properties in humans (reviewed in Boskou 2006; Cicerale et al. 2012; Covas et al. 2009). However, studies on its metal chelating properties when fed to animals are completely lacking. When we first noted that $B$. oleae was manganese-deficient and showed low iron and zinc accumulation compared to other Bactrocera species, we wondered whether this could be due to the addition of olive oil to its diet. Our attempt to address this question in D. melanogaster was hindered with a surprising high mortality at all stages of the life cycle. We were able to collect enough survivors for one comparative experiment (with flies cultivated on a normal diet in parallel), the results of which showed a drop in all metals in theDrosophila flies fed with olive oil (Table 5). The experiment with the Tephritid C. capitata could be repeated a number of times and showed a statistically significant drop in iron, copper and zinc but not manganese (although it should be noted that some other component in the $B$. oleae diet may be acting as a strong manganese chelator). Ceratitis capitata has been broadly used as a model for nutritional studies (Chang et al. 2000; Nash and Chapman 2014; Nestel et al. 2004, 2005; Papanastasiou et al. 2013) and we suggest that it could also become a good model system to investigate hypotheses regarding the metabolism and nutrition of metals.

Storage of metals versus co-factor requirements

Our results showed a very similar overall pattern of metal accumulation in Drosophilidae and Tephritidae in spite of cultivating these flies on different media. A working hypothesis to explain the metal conservation is that transition metals are required primarily as cofactors on vital metabolic enzymes and zinc for transcription factors, metalloproteases, carbonic anhydrase. Thus, the metallation of the proteins carrying out the insect's physiological requirements is reflected in the relative stable accumulation pattern of metals across the two Diptera families. When iron availability is manipulated in the diet, there is a corresponding change in the iron storage protein ferritin (Georgieva et al. 1999; Jiang et al. 2014; Missirlis et al. 2006, 2007; Tang and Zhou 2013), which would be the second-and more flexible-way to change insect metal accumulation without affecting its physiology. However, apart from insect ferritins (Pham and Winzerling 2010), we know very little about metal storage in the case of the other metals (Gutierrez et al. 2013). Excess copper, for example, frequently used as an insecticide, directly affects insect immunity (Polkki et al. 2012) and readily accumulates in flies (Bettedi et al. 2011), possibly bound to metallothioneins (McNulty et al. 2001; Egli et al. 2006). Some variability in metal accumulation can be attributed to a change in storage capacity, as seen in the differential ferritin accumulation in $D$. virilis and $D$. erecta (Sadraie and Missirlis 2011). However, it is at present difficult to study the same question for the other metals in the absence of concrete knowledge of their storage systems. A further complication could arise from the fact that insects appear to use different metalloenzymes during their different stages of development 
(Marelja et al. 2014), calling for metal storage mechanisms to remain operational also during developmental progression (Gonzáles-Morales et al. 2014; Tang and Zhou 2013). The small size of insects makes a tissue-by-tissue analysis difficult, yet tissue specificity of metal accumulation (Mehta et al. 2009) would also be informative regarding the internal mobilization and use of the metal ions. The role of the intestinal microbiota in metal absorption (Ben-Yosef et al. 2010; Erkosar Combe et al. 2014; Hobbie et al. 2012) and the role of symbionts, such as Wolbachia, that interact with the host's metabolism (Kosmidis et al. 2014; Kremer et al. 2009) should also be considered. Finally, hematophagous insects are bound to have developed specialized strategies against metals because of their specialized diet (Ribeiro et al. 2014; Zhou et al. 2007). Nevertheless and despite of all the variables that remain to be tested, the major conclusion of the study was that metal homeostasis is conserved in many species of fruit flies.

Acknowledgments The authors thank David Bignell for his insightful comments on an earlier draft of the manuscript and Yoav Gazit for providing the Israel laboratory stock of the Mediterranean fruit fly. This work was supported by the Consejo Nacional de Ciencia y Tecnología project\#179835, by the FAO/ IAEA and by the Chief Scientist Fund, Ministry of Agriculture of Israel.

Open Access This article is distributed under the terms of the Creative Commons Attribution License which permits any use, distribution, and reproduction in any medium, provided the original author(s) and the source are credited.

\section{References}

Afshar N, Argunhan B, Bettedi L, Szular J, Missirlis F (2013) A recessive $\mathrm{X}$-linked mutation causes a threefold reduction of total body zinc accumulation in Drosophila melanogaster laboratory strains. FEBS open bio 3:302-304. doi:10.1016/ j.fob.2013.07.003

Aluja M, Norrbom AL (1999) Fruit flies (Tephritidae): phylogeny and evolution of behavior. CRC Press, Boca Raton

Bahadorani S, Bahadorani P, Marcon E, Walker DW, Hilliker AJ (2010) A Drosophila model of Menkes disease reveals a role for DmATP7 in copper absorption and neurodevelopment. Dis Model Mech 3:84-91. doi:10.1242/dmm. 002642

Barajas-Aceves M (2005) Comparison of different microbial biomass and activity measurement methods in metal-contaminated soils. Bioresour Technol 96:1405-1414. doi:10. 1016/j.biortech.2004.09.013

Ben-Yosef M, Aharon Y, Jurkevitch E, Yuval B (2010) Give us the tools and we will do the job: symbiotic bacteria affect olive fly fitness in a diet-dependent fashion. Proccedings of the Royal Society of London B 277:1545-1552. doi:10. 1098/rspb.2009.2102

Bettedi L, Aslam MF, Szular J, Mandilaras K, Missirlis F (2011) Iron depletion in the intestines of Malvolio mutant flies does not occur in the absence of a multicopper oxidase. J Exp Biol 214:971-978. doi:10.1242/jeb.051664

Beverley SM, Wilson AC (1984) Molecular evolution in Drosophila and the higher Diptera II. A time scale for fly evolution. J Mol Evol 21:1-13

Bonilla-Ramirez L, Jimenez-Del-Rio M, Velez-Pardo C (2011) Acute and chronic metal exposure impairs locomotion activity inDrosophila melanogaster : a model to study Parkinsonism. Biometals 24:1045-1057. doi:10.1007/ s10534-011-9463-0

Boskou D (2006) Olive oil chemistry and technology. AOCS Press, Champaign

Briante R, Febbraio F, Nucci R (2003) Antioxidant properties of low molecular weight phenols present in the mediterranean diet. J Agric Food Chem 51:6975-6981. doi:10.1021/jf034471r

Chang CL, Kurashima R, Albrecht C (2000) Effect of limiting concentrations of growth factors in mass rearing diets for Ceratitis capitata larvae (Diptera: Tephritidae). Ann Entomol Soc Am 93:898-903. doi:10.1603/0013-8746 (2000)093[0898:EOLCOG]2.0.CO;2

Cicerale S, Lucas LJ, Keast RS (2012) Antimicrobial, antioxidant and anti-inflammatory phenolic activities in extra virgin olive oil. Curr Opin Biotechnol 23:129-135. doi:10. 1016/j.copbio.2011.09.006

Clark AG et al (2007) Evolution of genes and genomes on the Drosophila phylogeny. Nature 450:203-218. doi:10.1038/ nature 06341

Covas MI, Konstantinidou V, Fito M (2009) Olive oil and cardiovascular health. J Cardiovasc Pharmacol 54:477-482. doi:10.1097/FJC.0b013e3181c5e7fd

Cyert MS, Philpott CC (2013) Regulation of cation balance in Saccharomyces cerevisiae. Genetics 193:677-713. doi:10. 1534/genetics.112.147207

De Meyer M, Copeland RS, Lux SA, Mansell M, Quilici S, Wharton R, White IM, Zenz NJ (2002) Annotated check list of host plants for Afrotropical fruit flies (Diptera: Tephritidae) of the genus Ceratitis. Koninklijk Mus noor Midden Afr Tervuren Belge, Zoöl Doc 27:1-91

Egli D, Yepiskoposyan H, Selvaraj A, Balamurugan K, Rajaram R, Simons A, Multhaup G, Mettler S, Vardanyan A, Georgiev O, Schaffner W (2006) A family knockout of all four Drosophila metallothioneins reveals a central role in copper homeostasis and detoxification. Mol Cell Biol 26:2286-2296. doi:10.1128/MCB.26.6.2286-2296.2006

Erkosar Combe B, Defaye A, Bozonnet N, Puthier D, Royet J, Leulier F (2014) Drosophila microbiota modulates host metabolic gene expression via IMD/NF-kappaB signaling. PLoS ONE 9:e94729. doi:10.1371/journal.pone.0094729

FAO/IAEA/USDA (2003) Manual for product quality control and shipping procedures for sterile mass reared tephritid fruit flies, Version 5.0. IAEA. IAEA, Vienna, p 85

Forbes AA, Powell TH, Stelinski LL, Smith JJ, Feder JL (2009) Sequential sympatric speciation across trophic levels. Science 323:776-779. doi:10.1126/science.1166981

Freeman AA, Mandilaras K, Missirlis F, Sanyal S (2013) An emerging role for Cullin-3 mediated ubiquitination in sleep 
and circadian rhythm: insights from Drosophila. Fly 7:39-43. doi:10.4161/fly.23506

Georgieva T, Dunkov BC, Harizanova N, Ralchev K, Law JH (1999) Iron availability dramatically alters the distribution of ferritin subunit messages in Drosophila melanogaster. Proc Natl Acad Sci USA 96:2716-2721

Godfrey LV, Glass JB (2011) The geochemical record of the ancient nitrogen cycle, nitrogen isotopes, and metal cofactors. Methods Enzymol 486:483-506. doi:10.1016/ B978-0-12-381294-0.00022-5

Gomes Silva J, Malavasi A (1993) The status of honeydew melon as a host of Anastrepha grandis (Diptera:Tephiritidae). Fla Entomol 76(3):516-519

Gonzáles-Morales N, Missirlis F, Mendoza-Ortiz MA, Blowes LM, Riesgo-Escovar JR (2014) Ferritin is required at multiple stages during the embryonic development of Drosophila melanogaster. PeerJ PrePrints 2:e301v1 doi:10.7287/peerj.preprints.301v1

Gutierrez L, Sabaratnam N, Aktar R, Bettedi L, Mandilaras K, Missirlis F (2010) Zinc accumulation in heterozygous mutants of fumble, the pantothenate kinase homologue of Drosophila. FEBS Lett 584:2942-2946. doi:10.1016/j. febslet.2010.05.029

Gutierrez L, Zubow K, Nield J, Gambis A, Mollereau B, Lazaro FJ, Missirlis F (2013) Biophysical and genetic analysis of iron partitioning and ferritin function in Drosophila melanogaster. Metallomics 5:997-1005. doi:10.1039/c3m t00118k

Han HY, Ro KE (2009) Molecular phylogeny of the family Tephritidae (Insecta: Diptera): new insight from combined analysis of the mitochondrial $12 \mathrm{~S}, 16 \mathrm{~S}$, and COII genes. Mol Cells 27:55-66. doi:10.1007/s10059-009-0005-3

Hancock DL, Hamacek EL, Lloyd AC, Elson-Harris MM (2000). The distribution and host plants of fruit flies (Diptera: Tephritidae) in Australia. Department of Primary Industries, Queensland, Information Series Q199067, pp $1-75$

Hansch R, Mendel RR (2009) Physiological functions of mineral micronutrients $(\mathrm{Cu}, \mathrm{Zn}, \mathrm{Mn}, \mathrm{Fe}, \mathrm{Ni}, \mathrm{Mo}, \mathrm{B}, \mathrm{Cl})$. Curr Opin Plant Biol 12:259-266. doi:10.1016/j.pbi.2009.05. 006

Hobbie SN, Li X, Basen M, Stingl U, Brune A (2012) Humic substance-mediated $\mathrm{Fe}(\mathrm{III})$ reduction by a fermenting Bacillus strain from the alkaline gut of a humus-feeding scarab beetle larva. Syst Appl Microbiol 35:226-232. doi:10.1016/j.syapm.2012.03.003

Hua H, Gunther V, Georgiev O, Schaffner W (2011) Distorted copper homeostasis with decreased sensitivity to cisplatin upon chaperone Atox1 deletion in Drosophila. Biometals 24:445-453. doi:10.1007/s10534-011-9438-1

Jiang XZ, Cong L, Niu JZ, Dou W, Wang JJ (2014) Alternative splicing contributes to the coordinated regulation of ferritin subunit levels in Bactrocerae dorsalis (Hendel). Sci Rep 4:4806. doi:10.1038/srep04806

Kosmidis S, Missirlis F, Botella JA, Schneuwly S, Rouault TA, Skoulakis EM (2014) Behavioral decline and premature lethality upon pan-neuronal ferritin overexpression inDrosophila infected with a virulent form of Wolbachia. Front pharmacol 5:66. doi:10.3389/fphar.2014.00066

Kremer N, Voronin D, Charif D, Mavingui P, Mollereau B, Vavre F (2009) Wolbachia interferes with ferritin expression and iron metabolism in insects. PLoS Pathog 5:e1000630. doi:10.1371/journal.ppat.1000630

Lang M et al (2012) Mutations in the neverland gene turned Drosophila pachea into an obligate specialist species. Science 337:1658-1661. doi:10.1126/science.1224829

Liquido NJ, Shinoda LA, Cunningham RT (1991) Host plants of the Mediterranean fruit fly (Diptera: Tephritidae): an annotated world review, vol 77. Miscellaneous Publications of the Entomological Society of America, Maryland, pp 1-52

Mandilaras K, Pathmanathan T, Missirlis F (2013) Iron absorption in Drosophila melanogaster. Nutrients 5:16221647. doi:10.3390/nu5051622

Marelja Z, Dambowsky M, Bolis M, Georgiou ML, Garattini E, Missirlis F, Leimkuhler S (2014) The four aldehyde oxidases of Drosophila melanogaster have different gene expression patterns and enzyme substrate specificities. J exp biol 217:2201-2211. doi:10.1242/jeb.102129

McNulty M, Puljung M, Jefford G, Dubreuil RR (2001) Evidence that a copper-metallothionein complex is responsible for fluorescence in acid-secreting cells of the Drosophila stomach. Cell Tissue Res 304:383-389. doi:10.1007/ s004410100371

Mehta A, Deshpande A, Bettedi L, Missirlis F (2009) Ferritin accumulation under iron scarcity in Drosophila iron cells. Biochimie 91:1331-1334. doi:10.1016/j.biochi.2009.05. 003

Missirlis F, Holmberg S, Georgieva T, Dunkov BC, Rouault TA, Law JH (2006) Characterization of mitochondrial ferritin in Drosophila. Proc Natl Acad Sci USA 103:5893-5898. doi:10.1073/pnas.0601471103

Missirlis F et al (2007) Homeostatic mechanisms for iron storage revealed by genetic manipulations and live imaging of Drosophila ferritin . Genetics 177:89-100. doi:10.1534/ genetics.107.075150

Mora M, Bonilla E, Medina-Leendertz S, Bravo Y, Arcaya JL (2014) Minocycline increases the activity of superoxide dismutase and reduces the concentration of nitric oxide, hydrogen peroxide and mitochondrial malondialdehyde in manganese treated Drosophila melanogaster. Neurochem Res 4:1-9. doi:10.1007/s11064-014-1309-z

Nash WJ, Chapman T (2014) Effect of dietary components on larval life history characteristics in the Mediterranean fruit fly (Ceratitis capitata: Diptera, Tephritidae). PLoS ONE 9:e86029. doi:10.1371/journal.pone.0086029

Nestel D, Nemny-Lavy E, Chang CL (2004) Lipid and protein loads in pupating larvae and emerging adults as affected by the composition of mediterranean fruit fly (Ceratitis capitata) meridic larval diets. Arch Insect Biochem Physiol 56:97-109. doi:10.1002/arch.20000

Nestel D, Papadopoulos NT, Liedo P, Gonzales-Ceron L, Carey JR (2005) Trends in lipid and protein contents during Mediterranean fruit fly aging: an harmonic path to death. Arch Insect Biochem Physiol 60:130-139. doi:10.1002/ $\operatorname{arch} .20091$

Norgate M et al (2010) Syntaxin 5 is required for copper homeostasis in Drosophila and mammals. PLoS ONE 5:e14303. doi:10.1371/journal.pone.0014303

Paiva-Martins F, Gordon MH (2005) Interactions of ferric ions with olive oil phenolic compounds. J Agric Food Chem 53:2704-2709. doi:10.1021/jf0481094 
Papanastasiou SA, Nakas CT, Carey JR, Papadopoulos NT (2013) Condition-dependent effects of mating on longevity and fecundity of female medflies: the interplay between nutrition and age of mating. PLoS ONE 8:e70181. doi:10. 1371/journal.pone.0070181

Pham DQ, Winzerling JJ (2010) Insect ferritins: typical or atypical? Biochim Biophys Acta 1800:824-833. doi:10. 1016/j.bbagen.2010.03.004

Polkki M, Kangassalo K, Rantala MJ (2012) Transgenerational effects of heavy metal pollution on immune defense of the blow fly Protophormia terraenovae. PLoS ONE 7:e38832. doi:10.1371/journal.pone.0038832

Ribeiro JM et al (2014) An insight into the transcriptome of the digestive tract of the bloodsucking bug Rhodnius prolixus. PLoS Negl Trop Dis 8:e2594. doi:10.1371/journal.pntd. 0002594

Sadraie M, Missirlis F (2011) Evidence for evolutionary constraints in Drosophila metal biology. Biometals 24: 679-686. doi:10.1007/s10534-011-9420-y

Sanokawa-Akakura R et al (2010) Control of Alzheimer's amyloid beta toxicity by the high molecular weight immunophilin FKBP52 and copper homeostasis in Drosophila. PLoS ONE 5:e8626. doi:10.1371/journal.pone.00086 26

Sharon G, Segal D, Ringo JM, Hefetz A, Zilber-Rosenberg I, Rosenberg E (2010) Commensal bacteria play a role in mating preference of Drosophila melanogaster. Proc Natl Acad Sci USA 107:20051-20056. doi:10.1073/pnas.100 9906107

Singh SK, Sinha P, Mishra L, Srikrishna S (2013) Neuroprotective role of a novel copper chelator against abeta 42 induced neurotoxicity. Int J Alzheimer's Dis 2013:567128. doi: $10.1155 / 2013 / 567128$

Soriano S et al (2013) Deferiprone and idebenone rescue frataxin depletion phenotypes in a Drosophila model of Friedreich's ataxia. Gene 521:274-281. doi:10.1016/j. gene.2013.02.049

Southon A, Burke R, Camakaris J (2013) What can flies tell us about copper homeostasis? Metallomics 5:1346-1356. doi:10.1039/c3mt00105a

Stratikopoulos EE, Augustinos AA, Pavlopoulos ID, Economou KP, Mintzas A, Mathiopoulos KD, Zacharopoulou A (2009) Isolation and characterization of microsatellite markers from the Mediterranean fruit fly, Ceratitis capitata: cross-species amplification in other Tephritidae species reveals a varying degree of transferability. Mol Genet Genomics 282:283-306. doi:10.1007/s00438-009-0465-3

Tang X, Zhou B (2013) Ferritin is the key to dietary iron absorption and tissue iron detoxification in Drosophila melanogaster. FASEB J 27:288-298. doi:10.1096/fj.12213595

Tzanakakis ME (2003) Seasonal development and dormancy of insects and mites feeding on olive: a review. Neth J Zool 52:87-224. doi:10.1163/156854203764817670

Visioli F, Galli C (2002) Biological properties of olive oil phytochemicals. Crit Rev Food Sci Nutr 42:209-221. doi:10.1080/10408690290825529

Warburg MS, Yuval B (1996) Effect of diet and activity on lipid levels of adult Mediterranean fruit fly. Physiol Entomol 21:151-158

White IM, Elson-Harris MM (1994) Fruit flies of economic significance: their identification and bionomics. CAB International, Oxon

Wulbeck C, Simpson P (2000) Expression of achaete-scute homologues in discrete proneural clusters on the developing notum of the Mediterranean fruit fly Ceratitis capitata, suggests a common origin for the stereotyped bristle patterns of higher Diptera. Development 127:1411-1420. doi:10.1016/j.mod.2010.05.001

Xiao G, Wan Z, Fan Q, Tang X, Zhou B (2014) The metal transporter ZIP13 supplies iron into the secretory pathway in Drosophila melanogaster. eLife 3:e03191. doi:10.7554/ eLife.03191

Yang Y, Wu Z, Kuo YM, Zhou B (2005) Dietary rescue of fumble-a Drosophila model for pantothenate-kinaseassociated neurodegeneration. J Inherit Metab Dis 28: 1055-1064. doi:10.1007/s10545-005-0200-0

Zhou G, Kohlhepp P, Geiser D, Frasquillo Mdel C, VazquezMoreno L, Winzerling JJ (2007) Fate of blood meal iron in mosquitoes. J Insect Physiol 53:1169-1178. doi:10.1016/j. jinsphys.2007.06.009

Zur T, Nemny-Lavy E, Papadopoulos NT, Nestel D (2009) Social interactions regulate resource utilization in a Tephritidae fruit fly. J Insect Physiol 55:890-897. doi:10. 1016/j.jinsphys.2009.05.013 